\title{
Tourisme et création : les hypermodernes
}

\section{Anne Gombault}

\section{OpenEdition}

\section{Journals}

Édition électronique

URL : http://journals.openedition.org/tourisme/449

DOI : 10.4000/tourisme.449

ISSN : 2492-7503

\section{Éditeur}

Éditions touristiques européennes

\section{Édition imprimée}

Date de publication : 1 décembre 2011

Pagination : 18-35

ISSN : 2109-5671

\section{Référence électronique}

Anne Gombault, "Tourisme et création : les hypermodernes », Mondes du Tourisme [En ligne], 4| 2011 , mis en ligne le 30 septembre 2015, consulté le 19 avril 2019. URL : http://journals.openedition.org/ tourisme/449; DOI : 10.4000/tourisme.449

\section{cc) (i) $९$}

Mondes du tourisme est mis à disposition selon les termes de la licence Creative Commons Attribution - Pas d'Utilisation Commerciale - Pas de Modification 4.0 International. 


\title{
Tourisme et création : les hypermodernes
}

\begin{abstract}
ANNE GOMBAULT
[anne.gombault@bem.edu]

Professeur de management stratégique et comportement des organisations, responsable de la chaire Arts, Culture et Management en Europe - BEM - Bordeaux Management School
\end{abstract}

Résumé. Cet article présente une revue de littérature, ancrée en sciences de gestion et en économie, des travaux qui explorent et affirment la création comme une contribution essentielle à l'industrie du tourisme. Émergents depuis la fin des années 1990, ces travaux s'inscrivent dans un paradigme hypermoderne par les nouveaux comportements des producteurs et des consommateurs qu'ils analysent. Deux approches forment cette littérature. Dans les travaux sur la nouvelle économie de la culture et les industries créatives qui la constituent, le tourisme est catégorisé comme une industrie créative. Dans les travaux sur le tourisme, un courant a émergé sur le tourisme créatif, de nature expérientielle, qui étudie comment la création est présente dans les pratiques des acteurs du tourisme. Cette littérature émancipée a le mérite de balayer les oppositions anciennes entre culture, tourisme, économie et marketing en les intégrant au contraire fortement. Elle requiert cependant un examen attentif de l'instrumentalisation politique qui en est faite et donne lieu à de mauvaises pratiques, qu'elle a aussi dénoncées en son sein. Enfin, elle offre un agenda de recherche consistant et prometteur en sciences de gestion.

Abstract. This article presents a literature review, grounded in management sciences and economics, of studies that explore and affirm creation as a key contribution to the tourism industry. These studies began to emerge at the end of the 1990s, forming a hypermodernist paradigm resulting from the new behaviours demonstrated by the producers and consumers that are analysed. This literature is shaped by two approaches. In studies on the new economy of culture and creative industries of which it is made up, tourism is classed as a creative industry. In studies on tourism, a trend of creative tourism has emerged, experiential in nature, which looks at how creation is present in the practices of those in the tourism sector. This very liberated literature deserves credit for sweeping away the earlier conflicts between culture, tourism, economics and marketing and instead bringing them together very powerfully. However, a careful examination of the political use to which it has been put and which has given rise to some bad practice, which it has also denounced from within. Lastly, it provides a substantial and promising agenda for research in management sciences. 
D epuis la fin des années 1990, la nouvelle économie de la culture (Caves, 2000 ; Throsby, 200 I), venue des pays anglophones et désormais dominante au niveau mondial et européen $^{(1)}$, a défini le secteur culturel de façon extensive comme l'ensemble des creative industries ou "industries de la création", dites en français par convention industries créatives, en considérant les biens culturels comme des produits de création et comme des ressources stratégiques de développement économique et social durable. Dans ce cadre de référence, le tourisme est désormais catégorisé comme une industrie créative, faisant émerger la notion plus spécifique de tourisme créatif qui rejoint celle, plus large, de tourisme expérientiel. Dans une posture compréhensive et postmoderne, au sens où le discours de recherche, plus que le reflet du terrain, contribue à le construire (Atkinson, 1990), cette chronique présente une revue de la littérature consacrée à ce creative turn du tourisme contemporain (Richards et Wilson, 2007a, 2007b ; Richards, 20 I I), une fiction de cette littérature sur le tourisme et la création, c'est-à-dire une histoire sur les histoires de cette littérature, en détaillant les notions qui la définissent, leur articulation, leur intérêt et leurs limites. Les travaux de cette littérature, naturellement plutôt anglo-saxonne, se situent principalement en sciences de gestion - stratégie et marketing - et en économie, mais aussi en psychologie, en sociologie, en science politique, en géographie et en urbanisme, en sciences de l'information et de la communication. Ils peuvent être qualifiés de postmodernes (Urry, 1990 ; Firat et Venkatech, 1993 ; Rojek et Urry, 1997) et même, au-delà, d'hypermodernes (Lipovetsky, 2004, 2006 ; Aubert, 2004) ${ }^{(2)}$, à la fois par le nouveau comportement du consommateur qu'ils étudient ou qu'ils sous-tendent (individualiste désenchanté, angoissé et défiant, aux multiples identités et appartenances, en quête perpétuelle d'expériences, hédoniste, esthète, éclectique, réflexif, hyper ou alter consommateur mais toujours “consom'acteur") et par le nouveau comportement stratégique et organisationnel des acteurs du tourisme : le tourisme tend à disparaître, fondu dans la vie quotidienne, la culture et la consommation, dé-différencié des activités domestiques et de loisirs (Urry, 1990 ; McCabe, 2002), décloisonné lui-même et mélangeant les genres (Craik, 1997), à la fois global et local, présentéiste (surexploitant les signes du présent et surexplorant les symboles du passé), proposant un hyperchoix d'offres hyperréelles $^{(3)}$ (Perry, 1998 ; Poon, 1993 ; Graillot, 2005) qui permettent des expériences multiples, diverses, centrées sur la sensorialité, le design produit-service, une authenticité inventée, émergente des objets et du soi (Cohen, 1988 ; Wang, 1999), l'immédiateté, l'accessibilité, la technologie, la communication, les images...

\section{LE TOURISME, UNE INDUSTRIE CRÉATIVE}

Les industries créatives sont les "industries dans lesquelles le produit ou le service inclut une contribution essentielle de type artistique ou créatif, et qui sont habituellement porteurs de valeur artistique, culture ou de loisirs" (Caves, 2000 ; définition reprise par Barrère, 2006). Paris (2007) complète cette définition originelle en les désignant comme des "industries (au sens de 'secteur' ou 'filières') dans lesquelles le produit final est un objet de création", la création étant caractérisée comme "un processus, un acte par lequel un ou plusieurs créateurs conçoit” cet objet : "une oenvre, un message publicitaire, un plat culinaire, un dessin de produit...”. Deux remarques sémantiques peuvent être formulées pour comprendre la définition du concept. D'abord, la notion d “industries" est entendue au sens des industries de l'immatériel, fondées sur des actifs immatériels comme facteur majeur de production. L'expansion régulière de ces industries de l'immatériel, depuis la seconde moitié du $\mathrm{XX}^{\mathrm{e}}$ siècle, est caractéristique de l'apparition et du développement postfordiste de l'économie de la connaissance ou knowledge economy (Foray, 2000) - dont fait partie la nouvelle économie de la culture. Le régime d'innovation permanente de l'économie de la connaissance explique le recours massif au capital intangible; ce dernier aurait d'ailleurs dépassé le capital tangible dans le stock de capital réel. Dans ces indus- 
tries de l'immatériel, l'information, le savoir, les idées, la créativité, l'imagination, la capacité d'entreprendre sont désormais des facteurs clés de succès pour satisfaire la demande croissante de biens à fort contenu symbolique, sémiotique et esthétique des consommateurs hypermodernes (Barrère, 2006 ; Lash et Urry, 1994 ; Lipovetsky, 2006). Les industries créatives sont des industries de l'immatériel dont le facteur majeur de production est spécifiquement la créativité artistique et culturelle, et plus largement le droit de propriété intellectuelle, la gestion des talents et de l'innovation. Par conséquent, et c'est la seconde remarque sémantique, cette définition des creative industries ou "industries de la création" (Caves, 2000) comme industries de la créativité artistique et culturelle est à différencier de la notion générale de créativité (Galloway et Dunlop, 2006, 2007 ; Bilton, 2007)(4), que Throsby (2008) définit comme la capacité à produire des idées originales et inédites ou de nouvelles façons de résoudre des problèmes, alors que dans les industries de la création, la créativité d'un individu, d'un groupe, d'une entreprise, d'une industrie, d'un territoire fait référence à la qualité et à la quantité de contenus de création de tout ou partie de sa production (Paris, 2007).

\section{Catégorisation}

des industries de la création

La définition générique des industries de la création a permis de les identifier et de les catégoriser, telles qu'elles apparaissent, toutes défini- tions scientifiques et institutionnelles confondues (plus d'une dizaine recensées), à savoir : les arts visuels et le patrimoine $^{(5)}$; le spectacle vivant ; les industries culturelles traditionnelles, dont le cinéma et l'audiovisuel en général, la musique, l'édition, les jeux vidéos, les médias, etc. ; les services créatifs comme le design, l'architecture, la publicité, les relations publiques, les technologies de l'information et de la communication, l'éducation, la recherche, etc. ; les industries du goût comme l'artisanat, le luxe, la mode, la gastronomie, les vins et spiritueux, etc. ; les industries de loisirs et de divertissement comme le tourisme, l'hôtellerie, le sport, les parcs d'attractions, le jouet, les loisirs créatifs, etc. Le modèle des cercles concentriques du grand économiste de la culture australien Throsby (200 I), dont s'inspire la dernière définition britannique officielle (Work Foundation, 2007), fait apparaître quatre cercles qui permettent de classer ces différentes industries créatives en trois grandes catégories : - les activités de création artistique et culturelle (core creative fields ou core creative arts), c'est-à-dire les activités créatrices d'où viennent "les idées de création pure”. Ces activités sont définies par leur valeur d'expression (esthétique, spirituelle, sociale, historique, symbolique, authentique) ; elles requièrent la protection des droits de leurs auteurs;

- les industries culturelles, où les idées créatrices sont utilisées et reproduites comme input majeur dans le processus de production;

- les autres industries créatives, où les idées créatrices sont utilisées comme input dans le processus de production, sans pour autant constituer le principal ou le seul centre d'intérêt de ces industries (les services créatifs, les industries du goût, les industries de loisirs et de divertissement). Le tourisme fait partie de cette dernière catégorie.

Cette catégorisation du tourisme dans les industries créatives soustend deux postulats forts. D'une part, le tourisme serait intégré dans ce nouveau "grand champ culturel", autant marqueur que vecteur majeur de celui-ci, combiné aux autres industries créatives (Löfgren, 2003 ; Richards, 2009a). D'autre part, et inversement, la culture est à la fois un input du processus de production et un out$p u t$, c'est-à-dire à la fois une ressource et un produit du tourisme. Loin de la dichotomie classique entre un tourisme envahissant et une culture subissant, et des tensions entre les deux, qui domine la recherche sur le tourisme (Urry, 1990 ; Turner, 1992), les liens entre culture, tourisme et développement sont au contraire clairement affirmés dans une chaîne de valeur, au sens stratégique du terme (Porter, 1980), c'est-à-dire un ensemble d'activités interdépendantes qui permet de créer de la valeur identifiable et un avantage concurrentiel, et dont l'efficacité repose essentiellement sur la coordination des différents acteurs impliqués et sur leur capacité à former un réseau collaboratif. Les technologies de l'information ont favorisé un échange de données propice à une organisation efficiente de l'ensemble de la chaîne. 
La production et la valeur intrinsèque et extrinsèque du produit se réalisent dans cette chaîne de valeur (Becker, 1982 ; Paris, 2007 ; Richards et Wilson, 2008a). Le substrat central de cette nouvelle catégorisation du champ culturel consiste bien à lier les arts au commerce, et entre elles les industries créatives qui en sont issues (Caves, 2000) ; en d'autres termes, les arts, désormais "à l'état gazeux" (Michaud, 2003), se diffusent partout et suscitent une esthétisation de l'économie (Assouly, 2008). Il en résulte une hybridation croissante du tourisme (montrée plus largement par Craik, 1997) qui, de façon mimétique aux arts, aux industries culturelles et aux autres industries créatives en général, croise dans ses différents business models ${ }^{(6)}$, et donc dans ses processus de production, des industries créatives différentes. Barrère (2007), par exemple, décrit "une sorte de continuum" du plaisir ou du goût luxueux (au sens d'un "luxe démocratique, marchand, industriel, de masse") entre industries du voyage, de la restauration, de l'hôtellerie, du design et de la mode, du vin, du parfum... Le tourisme a toujours été une industrie créative, mais il ne l'a sans doute jamais été autant. Richards et Wilson (2007a, 2007b) ont commencé à explorer cette mutation actuelle, qu'ils qualifient de creative turn. Dans un marché en croissance, traversé à la fois par l'intensité de la concurrence et les attentes des nouveaux consommateurs, la création et la créativité artistique, culturelle et organisationnelle en général prennent une place de plus en plus importante dans les stratégies de développement du tourisme et dans leur marketing. Ainsi, ces stratégies sont de plus en plus imbriquées dans un large éventail d'autres industries créatives plus ou moins connexes : les loisirs bien sûr, le divertissement, le sport, les arts et la culture en général, l'éducation, le design, la gastronomie, l'œnologie, le goût plus largement, les médias, les technologies de l'information et de la communication, etc. Penser le tourisme comme une "industrie créative" a ouvert aux opérateurs privés et publics une réflexion stratégique passionnante autour du design de l'offre, qui produit cette hybridation : comment créer les conditions d'une expérience touristique à partir de l'offre d'autres industries créatives ? Tous les nouveaux concepts d'offres sont issus de cette réflexion planifiée ou émergente : éco, alter, techno, spirituel, fashion, sport, spa, ciné, gastro, œno, gay, urbain..., tourisme.

\section{Territoires créatifs}

"Glocal", le mouvement est spatialisé, la créativité s'incarnant largement dans des territoires et des lieux (Hanigan, 1998 ; Scott, 2000 ; Scott et Leriche, 2005 ; Richards, 2002, 2007, 2009b ; Richards et Wilson, 2008b). Dans la pensée de la nouvelle économie de la culture, l'avantage compétitif d'un territoire ou d'un lieu repose non plus sur sa richesse en matières premières (dans leur acception traditionnelle), ses industries manufacturières, le capital matériel ou une situation géographique particulière, mais sur le potentiel créatif et l'innovation qui existe sur ce territoire ou en ce lieu (Throsby, 2006) $)^{(7)}$. Une partie du monde, des continents, des pays, des régions, des villes, des quartiers, des rues, des banlieues, des campagnes, des îles, des océans, des rivières, des montagnes, des plages, des hôtels, des campings, des cafés, des restaurants, des casinos, des boutiques, des centres commerciaux, des entreprises, des aéroports, des gares ou des tramways, des crèches, des écoles et des campus, des maisons, des cimetières, des lieux de culte, des lieux sportifs et des lieux culturels eux-mêmes (musées, monuments, bibliothèques, théâtres, opéras, cinémas, salles de concerts...) sont devenus ou veulent devenir des creative spaces, des fabriques d'expériences créatives, par différentes stratégies ${ }^{(8)}$ qui font des industries créatives le vecteur du développement du territoire ou de leur développement propre (Lasalle et Britton, 2003 ; Richards et Wilson, 2007a, 2007b; Evans, 2007 ; Cloke, 2007). Mok (2010) rapporte l'exemple du questionnement stratégique de Hong Kong sur ses biens culturels localisés : "Quelles sont les ressources patrimoniales, historiques et culturelles de Hong Kong qui peuvent servir à renforcer mutuellement le développement des industries créatives en général et $d u$ tourisme en particulier? Quels sont les médias existants, les festivals et les biens culturels et les services culturels qui ont le potentiel de bénéficier aux industries créatives en général et au tourisme en particulier? Existe-t-il un mapping culturel et 
un audit des ressources culturelles qui peut nous aider à évaluer la maturité des marchés de consommation culturels? Quelles sont les forces et faiblesses des schémas institutionnels et organisationnels existants pour exploiter les ressources culturelles ?" La planification stratégique territoriale du développement des industries créatives en général et du tourisme en particulier est une question récurrente de la littérature. $\mathrm{Si}$, dans un premier temps, un certain nombre de ressources et de conditions structurelles, artistiques et culturelles, économiques et sociales doivent préexister pour favoriser l'émergence de ces industries, les territoires créatifs se dotent souvent, dans un second temps, de différents outils pour accompagner leur développement. L'importance de ces outils et de leur rôle dans le succès des stratégies mises en œuvre est très variable d'un territoire à l'autre (Lavanga, Stegmeijer et Haijen, 2008). Richards et Wilson (2007a, p. 18), étudiant les conditions d'émergence du tourisme comme industrie créative, distinguent trois types de structures nécessaires à celle-ci. Ce sont : le "creative hardware", c'est-à-dire les infrastructures et les espaces nécessaires à la production créative, ainsi que la consommation et la participation des consommateurs à la production (prosumption); le "creative software", c'est-à-dire les atmosphères et ambiances, les tendances, la qualité de vie, la diversité perçue, la vibration ou le rythme...; le "creative orgware”, c'est-à-dire les secteurs, les industries, les clusters, les districts, la politique, la gouvernance. Ils constatent que de nombreux territoires ayant déjà investi dans le "creative hardware" se sont tournés ces dernières années vers le "creative software" et le "creative orgware".

\section{LE TOURISME CRÉATIF, UN TOURISME EXPÉRIENTIEL}

Dans ce que Richards et Wilson appellent le "creative hardware", la participation des consommateurs à la production, dite "prosumption" ou "consom'action", a pris dans le tourisme, comme dans d'autres industries créatives, une importance toute particulière. Le terme "prosumption", issu de la contraction de production et de consumption, inventé par Alvin Toffler (1980) et popularisé par Tapscott (1995), désigne la volonté des consommateurs de participer directement à la création de leurs expériences de consommation, et donc à la création de valeur issue de ces expériences. La consommation n'est plus considérée comme un acte de réception passif d'une offre autonome mais comme un acte de production (Firat et Venkatesh, 1995). Cette nouvelle approche caractérise notamment l'activité de création de contenus, permise par les technologies interactives du web 2.0 que l'on trouve sur les plates-formes sociales ou sur les blogs, avec pour conséquence même si, parmi les accros de la Toile, les prosumers seraient minoritaires - une importante démocratisation de la création, au point de brouiller les frontières entre créateurs et consommateurs et de pousser les créateurs traditionnels à trouver de nouveaux business models qui banalisent la création et sa diffusion. Dans le contexte du tourisme, un courant spécifique de recherche s'est formé pour décrire ce phénomène de prosumption, baptisé creative tourism, littéralement "tourisme de la création”, et appelé par convention "tourisme créatif".

\section{Expériences touristiques créatives}

Après un tourisme de masse centré sur le "having holidays", puis un tourisme culturel de "must see sights", les consommateurs chercheraient à vivre des expériences touristiques créatives. Richards et Wilson (2006) en identifient trois types convergents : l'expérience d'activités spectaculaires ; l'expérience d'espaces créatifs ; la co-production d'autres activités créatives, le développement personnel servant de base à l'expérience touristique. Ce "tourisme créatif" est défini comme un tourisme qui offre l'occasion aux visiteurs de développer leur potentiel créatif à travers une participation active aux expériences caractéristiques offertes par la destination touristique, qui leur permet de se transformer (Richards et Raymond, 2000, p. 18 ; Binkhorst et Den Dekker, 2009). Il sous-tend que, par cette participation, le touriste devient l'habitant du territoire qu'il visite, qu'il fait partie de la communauté en cocréant avec elle et que l'habitant devient le touriste de son propre territoire, en le revisitant par la création. 
La co-création se réalise par la consommation expérientielle (voir infra) des produits de création, qui contribue à cette création, au plus proche de la culture des destinations (Smith, 2009) et selon différents modes : participation directe du touriste à la réalisation du produit de création ou bien construction d'une libre expérience à partir d'un ou de plusieurs produits de création. Le tourisme créatif fait finalement de la vie quotidienne du touriste, si ce n'est une œuvre d'art (Featherstone, |99|), au moins un produit de création. Par exemple, Binkhorst et Den Dekker (2007) analysent comment employés et touristes créent ensemble l'expérience de l'hospitalité.

Gommant ses frontières, il se substitue progressivement au "tourisme culturel” en réaction à l'insatisfaction des produits de ce dernier, et particulièrement à leur standardisation (Richards, 200I, 2005, 201 I ; Smith, 2005a ; Richards et Wilson, 2006; Binkhorst, 20 I0), issue d'une définition étroite du patrimoine (matériel, grands sites réputés, etc.) qui entraîne des effets pervers : dégradation de l'expérience due à la sur-fréquentation, éviction de différents publics, mimétisme de l'offre de tourisme culturel des villes et des territoires, autant d'effets encouragés par les institutions qui légitiment le tourisme culturel comme un "bon tourisme" (Cousin, 2008), le tout conduisant à une "serial reproduction" de la culture, à travers notamment les "megaevents" (comme les capitales européennes de la culture), les "iconic structures" (la "McGuggenheimi- zation", décrite par Honigsbaum, 200 I), l' "beritage mining”, la thématisation (avec les routes culturelles par exemple), le "hard-branding" culturel en général (Evans, 2003), dans un univers férocement concurrentiel. Richards et Wilson (2006) montrent avec ironie comment ces destinations, qui souhaitaient développer leur caractère unique à travers le tourisme culturel, ont en fait, suivant des stratégies similaires, produit des lieux uniformes qui ne se distinguent plus. Le tourisme créatif serait, a contrario du tourisme culturel, "actif plutôt que passif, portant sur l'apprentissage plutôt que sur l'apparence, sur le développement personnel autant que sur le développement économique" (Richards, 2005, pp 17-18). Il s'appuie sur l'identité des lieux visités, sur les traditions et les compétences locales et, plus largement, sur tous les caractères distinctifs d'une région (Binkhorst, 2007 ; Richards, 2005 ; Richards et Wilson, 2006), limitant ainsi le risque de "commodification" (Richards, 20 I0). Il renvoie aux analyses de Hagoort et Kooyman (20।0) sur les régions créatives qui mettent en avant l'importance des créateurs locaux. Par exemple, l'enquête de Maitland (2007) auprès des visiteurs d'Islington et de Bankside à Londres, qui devaient évaluer leur expérience vécue pendant le séjour, montrait clairement que l'attractivité de la destination ne se trouvait pas dans ses sites existants, mais dans son environnement distinct. À Islington, le visiteur remarquait l'environnement physique et culturel (l'architecture, l'ambiance cosmopolite) mais aussi les équipements de loisirs à disposition, boutiques, art, cafés, restaurants, boîtes de nuit. À Bankside, les visiteurs faisaient référence à l'architecture, la rivière, le paysage, l'histoire et l'atmosphère, qui étaient pour eux plus importants que la Tate Modern et le Shakespeare's Globe Theatre.

Déjà bien connues dans la gastronomie, l'œnologie ou le sport, les expériences de tourisme créatif sont aussi à développer dans l'art, l'artisanat, le design, les langues... (Meethan et Beer, 2007; Richards, 1999 , 2005). Plébiscité par les institutions (dont l'Unesco, l'OCDE, la Commission européenne...), l'essor du tourisme créatif repose sur les liens à bâtir avec les industries créatives locales, l'intention stratégique et l'entrepreneuriat des opérateurs du tourisme, le soutien des gouvernements locaux... Le Royaume-Uni, les États-Unis, le Canada, la Nouvelle-Zélande (Zahra, 2005 ; Richards et Wilson, 2006), l'Australie, l'Asie du Sud-Est, dont Singapour (Ooi, 2002, 2007) ou Hong Kong (Mok, 20 I0), l'Espagne et certaines capitales comme Berlin, Barcelone, Helsinki ou Montréal sont des exemples particulièrement avancés, là où d'autres grands pays du tourisme mondial, telles la France (Gombault, 20I0) ou l'Italie, n'ont pas encore fait leur mue.

\section{Valeur de l'expérience vécue par le consommateur}

Le tourisme créatif peut être décrit plus largement comme un tourisme fondamentalement expérientiel 
(Richards, 20I I). Apparu dans les années 1980, le marketing expérientiel a profondément renouvelé l'analyse du comportement du consommateur et le marketing des organisations (artistiques, culturelles, de divertissement, des loisirs et des industries créatives en général), qui étaient auparavant fondés seulement sur des déterminants économiques et sociaux. Dans cette nouvelle approche, la valeur attachée aux produits est abordée, de façon holistique, par le contenu de l'expérience vécue lors de leur consommation, pensée comme un état subjectif primaire provoqué par le symbolisme, l'hédonisme et l'esthétisme du produit (Hirschman et Holbrook, 1982a, 1982b). Du fait de leur forte dimension symbolique, les produits culturels ne peuvent pas être appréhendés à travers leurs seules composantes cognitives et exigent la prise en compte de l'affect du consommateur pour expliquer son comportement, la perspective cognitive ignorant les caractéristiques sensorielles, ludiques, esthétiques, émotionnelles de l'expérience vécue (Bourgeon et Filser, 1995). Le principe de plaisir est primordial dans la satisfaction retirée de l'expérience de consommation (Bourgeon et Bouchet, 2007). L'imaginaire et la gamme des affects y jouent un rôle majeur. Les travaux du psychologue Csikszentmihalyi (1990) montrent que la meilleure expérience (extrême) est celle dite de "flux" (flow), c'està-dire un moment exceptionnel (extraordinaire et inoubliable) pendant lequel ce que nous sentons, ce que nous souhaitons et ce que nous pensons sont en totale harmonie. Le consommateur "fait corps" avec l'expérience durant laquelle toute distance entre lui et le contexte situationnel est annulée. Mais ce consommateur ne veut pas seulement être immergé dans l'expérience, il cherche aussi à se l'approprier, en en étant le concepteur et le producteur actif, c'est-à-dire en s'engageant dans des processus inoubliables afin de vivre une "suite d'immersions" extraordinaires (Cova et Cova, 2004). Les professionnels, par les caractéristiques de leur offre, peuvent aussi l'amener à s'approprier l'expérience, mais le consommateur se l'approprie à la fois librement et conjointement avec eux, comme un jeu et non comme une confrontation, de diverses façons (en l'altérant ou la détournant par exemple). Urbain (2002), par exemple, a bien montré que les touristes autoproduisent leurs vacances. Ces notions clés d'immersion dans la réalité et d'appropriation de cette réalité permettent la co-création de l'expérience par le consommateur avec le producteur, ce qui définit les expériences les plus satisfaisantes (Sherry, 1998 ; Gentile, Spiller et Noci, 2007). Ce courant du comportement de consommation expérientielle reprend ici, en le poussant plus loin, l'argument de la recherche sociologique en comportement $\mathrm{du}$ consommateur, qui considère l'expérience comme un élément central de la vie quotidienne d'un consommateur en quête de sens : pour le consommateur postmoderne, la consommation n'est pas un pur acte de destruction des choses, ce n'est pas la fin d'un cycle économique, mais bien un acte de production des expériences, du soi et des images de soi (Vézina, 1999). Le marketing expérientiel de la culture a suscité pléthore d'enquêtes visant à comprendre l'expérience vécue du consommateur, notamment en proposant différentes typologies - pour une synthèse, voir Carù et Cova (2003). Retenons ici la nature foncièrement intersubjective de l'expérience de consommation culturelle, entre le(s) créateur(s) et le consommateur (one to one), qui conduit chacun à faire sa propre expérience et produit une infinie diversité d'expériences.

\section{Marketing expérientiel du tourisme}

Alors que le marketing expérientiel traverse largement le tourisme qui cherche à faire vivre aux touristes des expériences émotionnelles, sensorielles, culturelles, créatives, uniques et à forte valeur personnelle dans les lieux, les espaces, les situations, les services qu'ils expérimentent pour des motivations d'abord hédoniques (McIntosh et Siggs, 2005 ; Otto et Richie, 1996), et donc alors que le secteur est à l'évidence un des exemples pionniers de l'économie de l'expérience (Pine et Gilmore, 1998, 1999), comme l'ont montré les premiers travaux majeurs du champ dans les années 1970 (MacCannell, 1973, 1976; Dann, 1977 ; Cohen, 1979), c'est seulement récemment que des travaux de recherche ont développé et appliqué le courant du marketing expérientiel dans le tourisme. Ce 
sont évidemment les postmodernes qui ont reconnu la nature fondamentalement expérientielle du posttourisme : à cause d'elle, Urry (1990) affirme que le tourisme est la quintessence de l'industrie postmoderne, "une combinaison particulière $d u$ visuel, de l'esthétique et du populaire”, et Rojek et Urry (1997, p. 3) rappellent que le paradigme culturel postmoderne détruit toutes les distinctions conventionnelles entre la culture savante, populaire, la vie, la rue, l'ici et l'ailleurs... KirschenblattGimblett (1998) décrit le monde comme un vaste voyage de consommation expérientielle, qui propose toutes les "ways of escape" (Rojek, 1993), l'évasion étant une motivation expérientielle par excellence du tourisme. Smith (2005b) étudie le "new leisure tourist”, qui veut s'éclater, se divertir et pour cela dépense facilement de l'argent en un temps court. Au-delà du constat, la littérature sur le tourisme cherche à décrire et à comprendre des types d'expériences créatives : celles du patrimoine, matériel, dont naturel, ou immatériel (Hull et Harvey, 1989 ; Beeho et Prentice, 1997 ; Prentice, Witt et Hamer, 1998 ; Mclntosh et Prentice, 1999 ; Schanzel et Mclntosh, 2000 ; Goulding, 2000 ; Arnould et Thompson, 2005 ; Smith, 2006...), celles des activités d'aventure et de loisirs (Arnould et Price, 1993 ; Celci et al. ; Graillot, 2005 ; Bourdeau et Mao, 2002 ; Bourgeon et Bouchet, 2007 ; Corneloup et Mao, $2010 \ldots)$, celles du divertissement (Hughes et Benn, 1995 ; Belk, 1998 ; Ritzer et Stillman, 200 I ; Quatermaine et Peter, 2003 ; Bigné, Andreu et Gnoth,
2005 ; Graillot, 2005 ; Beeton, 2005...), celles du goût (Getz, 2000 ; Boniface, 2003...), celles des arts et du design (Kirschenblatt-Gimblett, 1998 ; Hughes, 2000 ; Ladwein, 2002 ; Munsters et Freund de Klumbis, 2005 ; Stipanuk, 2006 ; Maitland et Smith, 2009...). Mais la conceptualisation et la compréhension ou la mesure de ces expériences touristiques restent encore éparses (Quan et Wang, 2004 ; Gretzel, Fesenmaier, Formica et O'Leary, 2006; Oh, Fiore et Jeoung, 2007 ; Andersson, 2007 ; Yuan et Wu, 2008) et insuffisantes, notamment sur le rôle de la technologie, alors que la consommation et le marketing expérientiel sont au cœur des pratiques de l'industrie du tourisme, dans le contexte concurrentiel actuel. Comme l'écrit Sternberg, "les touristes sont des touristes parce qu'il veulent compenser le désenchantement, la sécularité et la banalité de leur vie par la confrontation temporaire à l'altérité - l'aventureux, l'étranger, l'ancien ou le spectaculaire. Les entreprises touristiques font leur affaire de concevoir, de produire et de vendre de telles expériences" (Stemberg, 1997, p. 954). Ainsi le tourisme créatif répond à la motivation du développement personnel, caractéristique de l'hypermodernité, et offre des expériences qui permettent une recherche d'authenticité existentielle, du "soi réel" (Selwyn, 1996), définie comme l'état existentiel potentiel d' "être", procuré par les activités touristiques (Wang, 1999). Longtemps oubliée dans la recherche sur le tourisme, tout occupée au débat entre objectivistes et construc- tivistes sur les "objets réels" mis en tourisme, cette forme d'authenticité, récemment reconsidérée par la littérature sur le tourisme (Wang, 1999; Olsen, 2002 ; Kim et Jamal, 2007), est celle du tourisme créatif par excellence. Par exemple, Daniel (1996) décrit la danse des touristes pendant les spectacles de danse dans des contextes touristiques comme des expériences "near-ecstatic". Autre exemple, à partir d'une étude qualitative sur le trekking comme expérience extraordinaire, Ladwein (2004) valide l'hypothèse selon laquelle le récit de l'expérience vécue, la mise en récit de soi - plus que le risque encouru - structure l'expérience de consommation, la valorise et la rend mémorable pour l'individu.

\section{VERTUS, LIMITES ET PISTES DE LA RECHERCHE SUR LE TOURISME ET LA CRÉATION}

Ce creative turn, qui peut être analysé comme une évolution majeure dans la production et la consommation de l'expérience touristique, offre un agenda de recherche important, notamment en sciences de gestion, encore peu étudié et convergent avec celui des loisirs, du divertissement, des arts et de la culture et des industries créatives en général.

\section{Vertus}

On aura compris, et pour autant que cela soit encore nécessaire, que faire du tourisme une industrie créative relativise fortement les vieilles 
critiques romantiques de l'instrumentalisation de la culture par le tourisme, et plus largement par l'économie et le marketing, parce que la culture utilise autant le tourisme comme une ressource que l'inverse, et parce que les deux étant inextricables et indissociables (Picard, 1992; Ooi, 2002), "l'opposition historique" et "le mépris réciproque" (Cousin, 2006) d'une culture originelle-gratuite-sacrée-autonome et d'un tourisme factice-marchand-profane-instrumental ne peuvent plus faire sens dans ce cadre théorique. De l'art pour l'art à la création en tout et pour tous, ce courant de recherche sur les industries créatives constate, dans la culture comme dans le tourisme, l'individualisation, la désacralisation, la "déhiérarchisation", la décentration des pratiques des consommateurs et des producteurs... C'est sa première grande vertu. Les nombreux détracteurs du marketing expérientiel de ces industries créatives, et précisément de la culture (Finkielkraut, 1987 ; Fowler, 1992 ; Debray, 1998 ; Aboudrar, 2000 ; Stiegler, 2004, 2005...) et du tourisme (Boorstin, 1964 ; MacCannell, 2005...) - impossibles à recenser ici tant ils sont nombreux -, évoquent pêlemêle, et entre autres, avec colère, cynisme ou ironie, le néo-libéralisme, la confusion des valeurs "le divertissement qui vaut culture”, la perte du sens originel, l'obsession et la prétention esthétique, la marchandisation, la simulation, la "McDisneyization" et autres néologismes péjoratifs (Ritzer, 1999 ; Ritzer et Liska, 2007), pour dénoncer, dans le sillage de Baudrillard (1977) ou d'Eco (1985), l'hyperréalité qu'il instaure. Ce discours dresse un diagnostic sévère à l'encontre des nouvelles techniques de médiation, qui, comme l'a décrit Ooi (2002, p. 25), sélectionnent, esthétisent, accentuent les artefacts culturels et conduisent à cette hyperréalité du tourisme (voir aussi l'intéressant exemple du marché de Noël de Strasbourg, étudié par Hertrich, Roederer et Badot, 20 I0). Il fustige la mystification à l'œuvre dans ces mises en scène de l'authenticité, alibi de stratégies commerciales démagogiques. Cette résistance idéologique se structure sur deux idées fortes : d'une part, la critique de la désacralisation du patrimoine, de ses œuvres et de son projet culturel originel et, d'autre part, la critique de la culture de masse. Elle s'inscrit en cela dans la lignée des réflexions de Benjamin (1939), puis surtout d'Adorno et Horkheimer (1947), philosophes de l'école de Francfort, nostalgiques d'une expérience culturelle authentique libre de toute technique, qui dénonçaient déjà "la dépravation de la culture” entraînée par une industrie culturelle mêlant culture et divertissement et privilégiant la rationalité technique et la standardisation. Le développement du marketing des industries créatives et son alliance, désormais objective, avec le tourisme marquent en effet, sans nul doute, la transformation des arts, du patrimoine et de la culture en industries de la création, c'est-à-dire en lieux de production, autant que de reproduction, d'expériences culturelles. Le déplorer revient à nier l'identité contemporaine de la culture et du tourisme, effectivement préoccupés par la désacralisation de leur identité traditionnelle, bourgeoise et élitiste, au profit de leur accessibilité, de la prise en compte des nouveaux comportements de consommation culturelle et de leur ancrage dans la société du XXI siècle. Plutôt que de s'en effarer, il est au contraire possible de s'en réjouir (Gombault, 2009).

Cela n'empêche pas que la littérature qui l'étudie, distanciée, regarde aussi de près les externalités, positives comme négatives, de cette alliance de la culture avec les autres industries créatives et de son implémentation, sous l'angle intéressant de la valeur. L'une des spécificités des industries créatives est de produire de la valeur culturelle et de la valeur économique (Throsby, 2008). La valeur culturelle comprend l'ensemble des valeurs intrinsèques de la culture, tandis que la valeur économique renvoie aux valeurs extrinsèques de la culture, valeurs de nature économique que sont l'emploi, le revenu, le produit intérieur brut (PIB), autrement dit la croissance économique. Comme l'explique Greffe (2007), dans un contexte d'économie de marché où l'autonomie de la création fonctionne difficilement car il lui faut trouver une demande solvable, les industries créatives, définies comme un ensemble de contrats entre les arts et le commerce (Caves, 2000), proposent une re-légitimation sociétale de l'art et de la culture par la mobilisation de valeurs extrinsèques ; c'est la deuxième grande vertu des 
recherches du domaine que de montrer cela. Cette mobilisation prend trois formes principales : économique, sociale et territoriale. D'abord, la fonction économique de l'art et de la culture est ancienne, avec notamment l'idée que la qualité des produits et le niveau de vie en seraient améliorés ; elle a déjà été exprimée, par exemple, en Occident et en Orient, au début de l'économie de marché et de la révolution industrielle, dans les arts décoratifs et le design, par les mouvements des Arts and Crafts, du Bauhaus, de l'Art nouveau, du Mingei au Japon, rapprochant l'art et de l'artisanat, etc. Cette fonction économique est revisitée depuis les années 1980 et largement explorée depuis : la culture est mobilisée tout à la fois comme une source de croissance économique en général, une consommation intermédiaire d'autres industries, un réenchantement de la consommation (Ritzer, 1999), un outil stratégique et marketing de l'entreprise. Ensuite, et comme le décrit Greffe (2007, p. 219), la fonction sociale de l'art et de la culture n'est pas nouvelle non plus ; depuis Aristote, en passant par Rousseau et jusqu'à la naissance du concept d'esthétique et les pensées de Hegel, de Shelley..., l'art et la culture étaient censés améliorer ceux qui en "bénéficiaient", sur les plans moral, émotionnel et spirituel. Audelà de l'économie, les industries créatives mettent en exergue cette fonction sociale (McCarthy, Ondjaate, Zakaras et Brooks, 2004) : la culture a valeur éducative, comme outil d'apprentissage de nouveaux savoirs, de socialisation, d'intégration sociale, de création d'un capital social. Enfin, dans un contexte de globalisation des échanges, les arts et la culture, en tant que biens "glocalisés”, revêtent une nouvelle importance dans la valorisation identitaire des territoires, comme une source importante d'avantage comparatif. Les industries créatives s'inscrivent fortement dans cette dimension spatiale, en faisant de la culture un outil de développement durable des territoires, vecteur d'attractivité, de tourisme et d'amélioration de la qualité de vie (Greffe, 2006).

\section{Limites}

Pour autant, la littérature s'accorde aussi majoritairement sur les limites de la surenchère euphorisante des valeurs extrinsèques de la culture, issue de la popularisation des mauvaises thèses de l'économie créative ${ }^{(9)}$ du gourou-consultant Richard Florida ${ }^{(10)}$ et de ses suiveurs, qui tendraient à faire oublier ses valeurs premières, fondamentalement intrinsèques. La communauté scientifique conteste fortement ces thèses, à la fois sur le plan théorique et méthodologique :

- déconnection de la créativité du champ culturel (Bilton, 2007 ; G. Tremblay, 2008);

- concepts discutables (pour une synthèse critique, voir Tremblay et Tremblay, 2010) - classe créative regroupant toutes les personnes amenant de la créativité au sens général dans leur emploi, agrégée autour des "3T" (technologie, talent, tolérance), trois index mobilisés par
Florida pour caractériser les villes aptes à attirer cette classe et à mieux mettre en valeur sa créativité ;

- causalités, corrélations et déductions fallacieuses dans ce qu'ils analysent (Garnham, 2005), notamment l'idée que l'attraction d'une "classe créative" permettrait la croissance des villes. Sur ce point, la complexité de l'impact économique et social des industries créatives et des processus à l'œuvre est rappelée par les économistes (Bille et Schultze, 2006), les géographes du solide courant de la "nouvelle économie géographique" (Kotkin, 2000 ; Glaeser, 2005) ${ }^{(11)}$ et les politologues du domaine, notamment britanniques, qui étudient particulièrement le sujet aujourd'hui, en raison de la politique mise en œuvre au Royaume-Uni. Appelant à la vigilance, ils stigmatisent le phénomène de "pensée magique" (Gombault et Livat-Pécheux, 2009) (12) $^{(22}$ à l'œuvre dans certains territoires, institutions et organisations, qui se sont emparés maladroitement du discours Florida, "nouvel Eldorado" (Paris, 2009) ${ }^{(13)}$, sans distance critique (McGuigan, 2009), et dénoncent le risque parfois avéré de "bullshit"(14) ou "rhétorique mensongère" des pouvoir publics due à leur incompétence (Belfiore, 2008), par exemple l'angélisme de la renaissance urbaine (Colomb, 2006, pp. 15-37; Vivant, 2009) qui fait l'impasse sur ses possibles externalités négatives (coût, expansionnisme urbain, "gentrification", instrumentalisation politique...), ou bien l'argument élastique du développement local par le tourisme (Cousin, 2007, pp. II-13), ou encore 
les enjeux géopolitiques tacites, comme en matière de diplomatie culturelle, de la rhétorique de l'économie créative, devenue, comme le tourisme culturel, "un lieu commun institutionnel" (Cousin, 2006), mais de façon bien plus répandue encore. Ils s'inquiètent à juste titre de certaines politiques publiques qui font des artistes et des créateurs en général les ouvriers les plus qualifiés des industries de la création, dont le tourisme (Markusen, 2004 ; Hughes, 2000 ; Greffe, 2007), au bénéfice d'autres acteurs (les élus, les chefs d'entreprise, les consommateurs, les citoyens) mais au détriment de leurs intérêts propres, leur autonomie étant réduite (risques d'un pur marketing de la demande) et leurs perspectives d'emploi et de revenus n'étant pas fondamentalement améliorées par une valorisation plus extrinsèque qu'intrinsèque des arts et de la culture (Gombault, Liot, Pralong, Agard et Morel, 20/2) - ce qui revient ici à une mauvaise compréhension et mise en œuvre de la nouvelle économie de la culture réconciliant, à l'inverse, le champ artistique et culturel avec celui de l'économie. Les gestionnaires de la culture rappellent sans cesse les spécificités stratégiques et organisationnelles de la création de valeur par la culture, qui reposent fondamentalement sur une économie prototypique de l'offre des créateurs (Caves, 2000), mais qui se construisent aussi, par les créatifs ${ }^{(15)}$, pendant la création tout au long de la chaîne amenant le produit au consommateur (Becker, 1982 ; Paris, 2007). Autrement dit, en termes écono- miques et stratégiques, il ne peut y avoir de valeurs extrinsèques sans valeurs intrinsèques, et vice versa (Greffe, 2007 ; Paris, 2007).

\section{Pistes de recherche}

À l'éclairage de la revue de littérature présentée dans cette chronique, l'agenda de recherche en sciences de gestion est pluriel :

- en marketing, le marketing expérientiel du tourisme et la participation des consommateurs à la production de l'expérience touristique, le marketing créatif des destinations et du tourisme dans les régions créatives ; - en finances et contrôle de gestion, la création de valeur et la performance du tourisme créatif ;

- en gestion des ressources humaines, la coopération des créateurs et des créatifs du tourisme ;

- en stratégie surtout, où l'exploration est d'abord nécessaire, avant d'aborder les autres disciplines de gestion, le concept d'industrie créative étant fondamentalement stratégique. La première question de recherche en stratégie (et idéalement de recherche-action, au plus près du terrain), pour l'avenir du développement du tourisme comme industrie créative, est de savoir comment le tourisme peut coopérer avec les autres industries créatives et mieux les intégrer - la résistance au changement étant encore forte chez de nombreux opérateurs et la dynamique entrepreneuriale, nécessaire -, en s'interrogeant sur la nature et la qualité des expériences qu'il offre à vivre aux visiteurs et sur les moyens d'en coproduire avec eux de plus créatives, au service de leurs attentes comme de celles des territoires et de leurs communautés; en d'autres termes, de mieux explorer "ce que peuvent apporter" les industries créatives au tourisme et "ce qu'il peut apporter" aux industries créatives. La seconde question de recherche liée est alors celle de la gouvernance, qui est de veiller à ce que, placé dans cette perspective, chacun des acteurs de la chaîne de valeur, dans le respect de ses finalités propres, puisse bien se développer, afin de limiter le nombre des exclus et des perdants, effet inhérent à cette hypermodernité (Aubert, 2004). Et pour le reste, enjoy...

\section{NOTES}

( I) Depuis l'agenda culturel proposé par la Commission européenne au Forum européen de Lisbonne en 2007 (Commission européenne, 2007), et entériné par le Conseil européen la même année. Un de ses trois grands objectifs est de faire de la culture le catalyseur de la créativité.

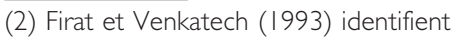
cinq caractéristiques d'une société postmoderne : I'hyperréalité, la fragmentation des expériences (autant de réalités différentes et décontextualisées), la primauté de la consommation comme fonction sociale identitaire (désormais déconnectée de la production), la construction de multiples identités pour l'individu décentré des repères traditionnels, l'éclectisme ou la juxtaposition des oppositions qui fait tout coexister. Dans une société hypermoderne qui va plus loin, en exagérant la modernité (Aubert, 2004, 
Lipovetsky, 2004, 2006), l'homme possède un nouveau corps : objectif (celui de l'âge) et subjectif. Ressentant de plus en plus d'anxiété, il chercherait à se réapproprier ce corps par sa sensorialité et souhaiterait vivre un maximum d'expériences en un minimum de temps et d'espace à parcourir. Fasciné par le présent et la performance, il est devenu un adepte du direct, de l'accessibilité, de l'instantanéité et du libre choix ("tout, tout de suite"), de la culture des loisirs. D'autres travaux émergent actuellement, précisément dans le tourisme et les loisirs (Corneloup et Mao, 2010), qui visent à réconcilier dans une transmodernité la pré-modernité, la modernité, la postmodernité et l'hypermodernité : ré-enchantement des temps anciens, temps et lien social, accessibilité et proximité, innovation durable, esthétique écologique.

(3) L'hyperréalité représente une réalité, différente de la réalité objective matérielle, générée par un processus de simulation de cette réalité ou déconnectée de celleci, qui conduit à ne plus pouvoir faire la différence entre le "vrai" et le "faux" (Perry, 1998). Les travaux de Graillot (2005) et de Badot (Badot et Graillot, 2006) identifient six modalités de mise en œuvre des univers ou sites hyperréels, et les étudient dans le contexte du tourisme de loisirs : leur thématisation (fondatrice, ludique, pédagogique, ornementale), la juxtaposition de dimensions plus ou moins hétérogènes ou contradictoires, la mise en scène de situation extrêmes et contrastées voire démesurées, l'accentuation des détails, un intérêt particulier pour un temps nostalgique, un contrôle des risques ou des sensations ou une suppression des inconvénients rencontrés dans la réalité, l'expérimentation d'un autre soi par immersion dans des expériences de consommation.

(4) Une forte controverse entre chercheurs et institutions a existé dans la littérature à propos de la première définition des industries créatives par le

Departement for Culture, Media and Sport du gouvernement travailliste britannique au début des années 2000, qui fait de la créativité individuelle leur fondement principal, sans référence particulière à la création artistique et aux contenus spécifiquement culturels. Cette controverse a posé utilement la question de savoir si cette catégorisation des industries créatives définissait largement les industries de la connaissance ou si elle définissait spécifiquement, parmi celles-ci, les industries de la création, ayant des inputs pour tout ou partie artistiques et culturels. Face à ces critiques et sous l'influence du travail originel de Caves (2000) et de celui, ensuite, de Throsby (200 I), la définition britannique a évolué dans ce sens des industries de la création (Work Foundation, 2007) qui domine progressivement la littérature sur le sujet. Les travaux centrés sur cette définition n'en étudient pas moins l'intrication entre la créativité des contenus artistiques et culturels et la créativité organisationnelle qui ressortit aux stratégies des industries créatives.

(5) Les arts et le patrimoine sont donc bien pensés ici comme une industrie de la création passée, présente et future : sur le patrimoine, voir par exemple les travaux de Barrère (2006, 2007 ; Barrère, Barthélemy, Nieddu et Vivien, 2005) et de Greffe $(2003,2007)$.

(6) Le business model peut être défini comme une convention de l'entreprise relative à la génération de la valeur, à la rémunération de celle-ci et à son partage avec les parties prenantes (Verstraete et Jouison-Laffitte, 201 I).

(7) Le rapport Lévy et Jouyet (2006), qui a popularisé le sujet dans les institutions françaises, s'inscrit dans cette pensée. Sur le cas spécifique de la France, voir Gombault (2009).

(8) Les exemples de creative spaces cités, et les différentes stratégies qui mènent à le devenir, forment une abondante littérature, qui n'est pas détaillée dans cette chronique.

(9) Si les acteurs institutionnels utilisent le terme de "creative economy", l'expression est peu utilisée dans le champ académique, qui préfère évoquer l'"économie de la culture" ou la "nouvelle économie de la culture". Le terme est d'abord associé aux travaux contestés de Florida (2002). L'ouvrage du consultant John Howkins (200 I), The Creative Economy, How People Make Money from Ideas, définit le terme dans une acception large "toutinformation", sans distinguer la création, ce qui est contesté par les chercheurs aujourd'hui (Throsby, 2008)

(10) Le phénomène "Richard Florida" est sans doute à la fois la meilleure et la pire des choses qui soit arrivée au développement des industries créatives. En 2002, ce chercheur publie The Rise of The Creative Class, où il développe ses thèses sur la classe créative. Très vite, l'ouvrage est un best-seller, réimprimé des dizaines de fois. Partout en Amérique du Nord, les maires invitent Richard Florida pour savoir comment attirer cette mystérieuse classe de l'avenir. Pour répondre à la demande, 
Florida fonde une entreprise de conseil, Catalytix Inc. et part en tournée mondiale de conférences, comme il l'explique sur son site internet ( $w w w . c r e a t i v e c l a s s . o r g)$. Excellent entrepreneur, il a su faire un marketing très "créatif" (!) de ses thèses. L'ensemble de la communauté académique en sciences sociales se penche alors sur ses travaux et sur le "phénomène Florida" : géographes, économistes, sociologues, gestionnaires... Tous lui reconnaissent d'avoir popularisé l'importance croissante des industries créatives dans l'économie, mais beaucoup fustigent les limites scientifiques de son discours et sa simplification rhétorique. Théorie qui fait plaisir, fourre-tout et nourrie des préjugés de l'époque, la charge est sévère. C'est d'abord l'élaboration insuffisante de concepts structurants dans la théorie qui est critiquée.

( I I) Ce courant s'accorde à penser que la thèse de Florida (2002) sur l'attractivité des villes créatives, capables d'attirer la "classe créative", source de développement, aussi séduisante soit-elle, ne vaudrait en réalité que pour des cas restreints, notamment quelques grandes métropoles, et qu'elle présenterait un intérêt seulement descriptif de la coprésence du capital humain qualifié et du développement régional-urbain déjà connu depuis longtemps, échouant à démontrer le sens de l'implication, considéré par la littérature comme indéterminé et difficile à établir.

(I2) Devant le constat de la montée en puissance de cette "pensée magique" de l'économie créative des acteurs de la culture et des politiques publiques en France, et de leur méconnaissance de la littérature sur la nouvelle économie de la culture et les industries créatives, ce petit handbook a été rédigé avec une vingtaine de chercheurs nationaux et internationaux, à l'attention de ces acteurs, pour les aider à mieux comprendre et à démêler cette littérature, et permettre ainsi, par un cadrage scientifique, une bonne coopération avec eux dans la conduite de recherches de terrain qu'ils commandent à la chaire Arts, culture et management en Europe. II propose, entre autres, une synthèse des travaux critiques. II devrait paraître dans une édition académique augmentée.

(13) "Non, les choses ne sont pas si simples. Les dynamiques de la création sont complexes, ses liens avec les institutions et avec les territoires le sont tout autant" (Paris, 2009, p. 8)

(14) Eleonora Belfiore (2008) utilise le concept de "bullshit" développé en 2005 par Frankfurt, professeur de philosophie morale à l'université de Princeton, dans un petit essai devenu un best-seller. Frankfurt (2005) analyse, à travers ce concept, la rhétorique et la pratique des politiques publiques contemporaines. Plusieurs chercheurs britanniques en science politique de l'université de Warwick, dont Belfiore, dénoncent la prévalence du bullshit dans la rhétorique et la pratique de la politique culturelle du Royaume-Uni, en montrant comment elle illustre parfaitement ce concept: "Lack of concern with truth, indifference to how things really are as well as the cultivation of vested interests."

$\overline{\text { (15) Paris (2007) }}$ rappelle la division du travail dans les industries créatives entre les créateurs ("ceux qui ont la responsabilité de la création et qui sont reconnus comme les auteurs") et les créatifs ("ceux qui participent à l'acte de création").

\section{RÉFÉRENCES BIBLIOGRAPHIQUES}

Bruno-Nassim ABOUdRAR, Nous n'irons plus au musée, Aubier/Alto, 2000.

\section{Theodor ADORNO et Max HORKHEIMER, La}

Production industrielle de biens culturels dans La Dialectique de la raison, Gallimard, 1947 (nouv. éd., 1974).

Tommy D. ANDERSSON, "The tourist in the experience economy", Scandinavian Journal of Hospitality and Tourism, vol. 7, n I, 2007.

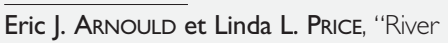
Magic: extraordinary experience and the extended service encounter", Journal of Consumer Research, 20, n I, 1993.

\section{Eric J. ARNOULD et Craig THOMPSON,}

"Making consumption magic: a study of white-water river rafting", Journal of Consumer Research, 31 (4), 2005

Olivier Assouly, Le Capitalisme esthétique. Essai sur l'industrialisation du goût, Cerf, 2008.

Paul ATKINsON, The Ethnographic Imagination: Textual Construction of Reality, Routledge, 1990.

Nicole AUBERT (dir.), L'Individu hypermoderne, Érès, 2004.

Olivier BADOT et Laurence GraILLOT, ، 'Marketing hyperréel' ou 'marketing méditerranéen' : tentative d'éclaircissement à partir du cas de l'enseigne L'Occitane", dans Antonella CARÙ et Bernard COVA (dir.), Marketing Mediterraneo tra Metafora e Territorio, éditions Egea, 2006.

Christian BARRÈRE, "Les liens entre culture, industries culturelles et industries créatives", dans Xavier GrefFE (dir.), Création et diversité au miroir des industries culturelles, La Documentation française, 2006.

Christian BARrère, "Les industries du luxe: des industries de patrimoines ?", Économie appliquée, n³ ("L'économie du patrimoine"), 2007. 


\section{CHRONIQUE SCIENTIFIQUE}

Christian BARRĖre, Denis BARTHélemY,

Martino NiEDDU et Franck-Dominique

VIVIEN, Réinventer le patrimoine. De la culture

à l'économie, une nouvelle pensée du

patrimoine ?, L'Harmattan, 2005

Jean BAUDRILLARD, L'Effet Beaubourg.

Implosion et dissuasion, Galilée, 1977.

Howard BECKER, Art Worlds, University of

California Press, 1982 (nouv. éd., 2006).

Alison J. BeeHo et Richard Prentice,

"Conceptualizing the experiences of heritage tourists: a case study of New Lanark World Heritage Village", Tourism Management, 18, $n^{\circ} 2,1997$.

Sue Beeton, Film-induced Tourism, Channel View, 2005.

Eleonora BELFIORE, "On bullshit in cultural policy practice and research", Proceedings of the 5th International Conference on Cultural Policy Research, Istanbul, 2008.

Russel W. Belk, "Three coins in a Caesar's Palace fountain: interpreting Las Vegas", dans Joseph W. AlBA et Wesley HUTCHINSON

(dir.), Advances in Consumer Research, vol. 25, Association for Consumer Research, Provo, UT, 1998.

Walter Benjamin, L' Fuvre d'art à l'heure de sa reproductibilité technique, Allia, 1939 (nouv. éd., 2005).

J. Enrique BIGNÉ, Luisa ANDREU et Juergen GNOTH, "The theme park experience: an analysis of pleasure, arousal and satisfaction", Tourism Management, 26, n 6, 2005.

\section{Trille BilLe et Günther G. SCHULTZE,}

"Culture in urban and regional

development", dans Victor A. GINSBURGH et David Throsby (dir.), Handbook of the Economics of Art and Culture, vol. I, NorthHolland, 2006.

Chris BILTON, Management and Creativity.

From Creative Industries to Creative

Management, Blackwell, 2007.
Esther BINKHORST, "Creativity in tourism experiences, a closer look at Sitges", dans Greg RICHARDS et Julie WILSON (dir.), Tourism, creativity and development,

Routledge, 2007.

Esther BINKHORST, "Blurring boundaries in cultural tourism research", dans Greg RICHARDS et Julie WILSON (dir.), Cultural Tourism Research Methods, Cabi, 2010.

Esther BINKHORST et Teun DEN DEKKER,

"How guests and employees co-create the hospitality experience", Extraordinary Experiences Conference, Bournemouth, 2007. $\overline{\text { Esther BINKHORST }}$ et Teun DEN DEKKER, "Agenda for co-creation tourism experience research", Journal of Hospitality Marketing and Management (numéro spécial "Experience Marketing'), vol. I8, n² 2-3, 2009.

Priscilla BONIFACE, Tasting Tourism: Travelling for Food and Drink, Ashgate, 2003.

Daniel Boorstin, The Image: A Guide to Pseudo-Events in America, Harper and Row, 1964.

Philippe Bourdeau et Pascal MaO, "Les nouveaux espaces de pratiques sportives de montagne et de nature", dans COLLECTIF, Les Espaces sportifs innovants, Presses universitaires du sport, 2002.

Dominique BOURGEON et Marc FILSER, "Les apports du modèle de recherche d'expériences à l'analyse du comportement dans le domaine culturel : une exploration conceptuelle et méthodologique", Recherche et Applications en Marketing, 10, n 4, 1995.

Dominique BOURGEON et Patrick BOUCHET,

"Marketing expérientiel et analyse des logiques de consommation du spectacle sportif', Revue française du marketing, $n^{\circ} 212$, 2007.

\section{Antonella CARÙ et Bernard Cova,}

"Revisiting consumption experience: a more humble but complete view of the concept",
Marketing Theory, 3, n² 2, 2003.

Richard CAVES, Creative Industries: Contracts Between Art and Commerce, Harvard University Press, 2000

Richard L. Celsi, Randall L. Rose, Thomas W. LEIGH, "An exploration of high-risk leisure consumption through skydiving", Journal of Consumer Research, 20, 1993.

Paul CLOKE, "Creativity and tourism in rural environments", dans Greg RICHARDS et Julie WILSON, Tourism, Creativity and Development, Routledge, 2007.

Erik COHEN, "A phenomenology of tourist experiences", Sociology, n 13, 1979.

Erik COHEN, "Authenticity and commoditization in tourism", Annals of Tourism Research, 1988.

Christelle ColomB, "Le new labour et le discours de la 'renaissance urbaine' au Royaume-Uni. Vers une revitalisation durable ou une gentrification accélérée des centresvilles britanniques ?", Sociétés contemporaines, $n^{\circ}$ 63, 2006.

COMMISSION EUROPÉENNE, Communication from the Commission to the European Parliament, the Council, the European Economic and Social Committee and the Committee of the Regions on a European agenda for culture in a globalizing world, Bruxelles, 2007.

Jean Corneloup et Pascal MAO (dir.), Créativité et innovation dans les loisirs sportifs de nature. Un autre monde en émergence,

Éditions du Fournel, 2010.

Bernard Cova et Véronique Cova,

"L'hyperconsommateur, entre immersion et sécession", dans Nicole AUBERT (dir.),

L'Individu hypermodeme, Érès, 2004.

Saskia Cousin, "Le 'tourisme culturel', un lieu commun ambivalent", Anthropologie et Sociétés, vol. 30, n² 2, 2006.

Saskia Cousin, "L'argument du développe- 
ment local par le tourisme", Actes de la recherche en sciences sociales, vol. $5, n^{\circ} 170$, 2007.

Saskia Cousin, “'L'Unesco et la doctrine du tourisme culturel. Généalogie d'un 'bon' tourisme", Civilisations, 57, 2008 .

Jennifer CRAIK, "The culture of tourism", dans Chris RoJek et John URRY, Touring Cultures: Transformations of travel and theory, Routledge, 1997.

Mihaly CSIKSZENTMIHALYI, Flow: the Psychology of Optimal Experience. Steps Toward Enhancing the Quality of Life, Harper and Row, 1990.

Yvonne Payne DANIEL, "Tourism dance performances: authenticity and creativity", Annals of Tourism Research, $n^{\circ} 23,1996$.

Graham M. S. DANN, “Anomie, ego-enhancement and tourism, Annals of Tourism Research, 4, n 4, 1977.

Régis Debray (dir.), L'Abus monumental ?, Actes des Entretiens du patrimoine, Fayard, 1998.

Umberto Eco, La Guerre du faux, Grasset et Fasquelle, 1985.

Graeme Evans, "Hard-branding the cultural city - from Prado to Prada", International Joumal of Urban and Regional Research, 27, $n^{\circ} 2,2003$.

Graeme Evans, "Creative spaces, tourism and the city", dans Greg RICHARDS et Julie WILSON, Tourism, Creativity and Development, Routledge, 2007.

Mike Featherstone, Consumer culture and post-modernism, Sage, 1991.

Alain FINKIELKRAUt, La Défaite de la pensée, Gallimard 1987.

\section{Fuat FiRAT et Alladi VeNKATESH,}

"Postmodernity: the age of marketing", International Joumal of Research in Marketing, vol. 10, 1993

Fuat Firat et Alladi VenKatesh, "Liberatory postmodernism and the reenchantement of consumption", Journal of Consumer Research, vol. 22, 1995.

Richard FLORIDA, The Rise of the Creative Class... And How It's Transforming Work, Leisure, Community and Everyday Life, Basic Books, 2002.

Dominique FORAY, L'Économie de la connaissance, La Découverte, 2000.

Peter J. Fowler, The Past in Contemporary Society. Then, Now, Routledge, 1992.

Harry G. Frankfurt, On Bullshit, Princeton University Press, 2005.

\section{Susan GALlowaY et Stewart DuNLOP,}

"Deconstructing the concept of "creative industries', dans Christiane EISENBERG, Rita GERLACH et Christian HANDKE, Cultural Industries: The British Experience in Intemational Perspective, Humbolt-Universität, 2006.

Susan Galloway et Stewart Dunlop, "A

critique of definitions of the cultural and creative industries in public policy", Intemational Journal of Cultural Policy, vol. I3, $n^{\circ}$ I, 2007.

Nicholas GARNHAM, "From cultural to creative industries: an analysis of the implications of the 'creative industries' approach to arts and media policy making in the United Kingdom", Intemational Journal of Cultural Policy, II, n I, 2005.

Chiara GentILE, Nicola SpILLeR et Giulano

Nocl, "How to sustain the customer experience: an overview of experience components that co-create value with the consumer", European Management Journal, 25 , $n^{\circ} 5,2007$.

Donald GETZ, Explore Wine Tourism: Management Development and Destination, Cognizant Communication Corporation, 2000

Edward L. GLAESER, "Review of Richard
Florida's The Rise of the Creative Class", Regional Science and Urban Economics, vol. 35, 2005.

Anne GombaULT, "Marketing du patrimoine", dans Dominique BOURGEON (dir.), Marketing de l'art et de la culture, Dunod, 2009.

Anne Gombault, "Creative industries in France: emergence of a new paradigm in a great old cultural nation", dans Y. D. LIN (dir.), Intemational Classic Statement of Cultural and Creative Industry, Taipei City, Shtabook, 2010.

\section{Anne GombaUlt, Françoise LıOT, Jean} Pralong, Jean-Yves AgARD, Catherine

MOREL, "Losers lose : les vrais outsiders des mondes de l'art contemporain", dans PierreJean BENGHOZI et Thomas PARIS, Howard Becker et les mondes de l'art, École polytechnique, 2012 (à paraître).

\section{Anne Gombault et Florine Livat-PÉCHEUX}

(dir.), Alphabem des industries créatives, Éditions BEM-Bordeaux Management School, 2009.

Christine GoULDING, "The museum environment and the visitor experience", European Journal of Marketing, vol. 34, n 3-4, 2000.

Laurence Graillot, "Réalités (ou apparences ?) de l'hyperréalité : une application au cas du tourisme de loisirs", Recherche et applications en marketing, 20, $n^{\circ}$ I, 2005, pp. 43-64.

Xavier Greffe, La Valorisation économique du patrimoine, La Documentation française, 2003.

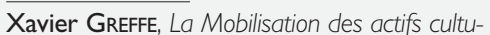
rels de la France. De l'attractivité culturelle du territoire... à la nation culturellement créative, Document de travail du Deps, ministère de la Culture et de la Communication, 2006. Xavier GrefFe, Artistes et marchés, La

Documentation française, 2007. 


\section{CHRONIQUE SCIENTIFIQUE}

Ulrike Gretzel, Daniel R. FesenMAIer, Sandro Formica et Joseph T. O'LEARY, "Searching for the future: challenges faced by destination marketing organizations", Journal of Travel Research, 45, n² 2, 2006. Giep Hagoort et Rene Kooyman (dir.), Creative Industries: Colourful Fabric in Multiple Dimensions, Eburon Academic Publishers, 2010.

John Hanigan, Fantasy City: Pleasure and Profit in the Post-Modem Metropolis, Routledge, 1998.

\section{Sylvie Hertrich, Claude Roederer et}

Olivier BADOT, "Comment un produit 'hyperréel' regagne-t-il un statut d"authenticité' ? Le cas du marché de Noël de Strasbourg", Actes des 15 es Journées de recherche en marketing de Bourgogne, 2010.

\section{Elizabeth C. HIRSCHMAN et Morris B.}

HOLBROOK, "Hedonic consumption: emerging concepts, methods and propositions", Journal of Marketing, 46, n 3, 1982a.

\section{Elizabeth C. Hirschman et Morris B.}

HOLBROOK, "The experiential aspects of consumption: consumer fantasies, feelings and fun", Joumal of Consumer Research, 9, $n^{\circ}$ 2, 1982b.

Mark HoniGSBAUM, "Saturday review: McGuggenheim? Motorbikes and Armani. Is this any way to run a great gallery?", The Guardian, 27 janvier 200 I.

John HowkIns, The Creative Economy: How People Make Money From Ideas, Penguin, 2001.

Howard HUGHES, Arts, Entertainment and Tourism, Butterworth Heinemann, 2000.

\section{Howard Hughes et Danielle BENN,}

"Entertainment: its role in the tourist experience", dans David LESLIE (dir.), Leisure and Tourism 2: Towards the Millennium, Leisure Studies Association, 1995.

R. Bruce Hull et Anthony HarveY,
"Explaining the emotion people experience in suburban parks", Environment and Behaviour, vol. 21, n 3, 1989.

Hyounggon KIM et Tazim JAMAL, "Touristic quest for existential authenticity", Annals of Tourism Research, vol. 34, n I, 2007.

\section{Barbara KIRSCHENBLATT-GIMBLETT,}

Destination Culture: Tourism, Museums and Heritage, University of California Press, 1998. Joel KotKIN, The New Geography, Random House, 2000.

Richard LADWEIN, "Voyage à Tikidad: de l'accès à l'expérience de consommation", Décisions marketing, $n^{\circ}$ 28, 2002.

Richard LADWEIN, "L'expérience de consommation et la mise en récit de soi : le cas du trekking", Actes des 9es Journées de recherche en marketing de Bourgogne, 2004.

\section{Diana LASAlle et Terry A. Britton,}

Priceless: Turning Ordinary Products into Extraordinary Experiences, Harvard Business School Press, 2003.

Scott LASH et John URRY, Economies of signs and space, Sage, 1994.

Mariangela LAvanga, Eva Stegmeljer et Joni HAIJEN, "Incubating creativity; unpacking locational and institutional conditions that can make cultural spaces and creative areas work", Proceedings of the 5 th International Conference on Cultural Policy Research,

Istanbul, 2008.

Marc LÉVY et Jean-Pierre JOUYET,

L'Économie de l'immatériel. La croissance de demain, Rapport de la commission sur l'économie de l'immatériel, ministère de l'Économie, des Finances et de l'Industrie, 2006.

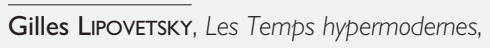
Grasset, 2004.

Gilles LIPOVETSKY, Le Bonheur paradoxal. Essai sur la société d'hyperconsommation, Gallimard, 2006.

Orvar LÖFGREN, "The new economy : a cul- tural history", Global Networks, vol. 3, n³, 2003.

Dean MaCCANNELL, "Staged authenticity: arrangements of social space in tourist settings", American Journal of Sociology, vol. 79 , $n^{\circ}$ 3, 1973.

Dean MacCanNelL, The Tourist: A New Theory of the Leisure Class, Schocken, 1976. Dean MACCANNELL, "The fate of the symbolic architecture for tourism: Piranesi, Disney, Gehry", dans Anna Maria GUASH et Joseba ZULAIKA (dir.), Leaming from the Bilbao Guggenheim, University of Nevada Press, 2005.

Robert MAITLAND, "Conviviality and everyday life: the appeal of new areas of London for visitors", Intemational Journal of Tourism Research, vol. 10, 2007.

\section{Robert MAITLAND et Andrew SMITH,}

"Tourism and the aesthetics of the built environment", dans John TRIBE (dir.), Philosophical Issues in Tourism, Channel View, 2009.

Ann Markusen, "Targeting occupations in regional and community economic development", Journal of the American Planning Association, vol. 70, n 3, 2004.

Wil Munsters et Daniela Freund De KLUMBIS, "Culture as a component of the hospitality product", Marianna SIGALA et David LESLE (dir.), Intemational Cultural Tourism: Management, Implications and Cases, Butterworth Heinemann, 2005.

Scott MCCABE, "The tourist experience and everydaylife", dans Graham M. S. DANN

(dir.), The Tourist as a Metaphor of the Social Worlds, Cabi, 2002.

Kevin F. MCCARTHY, Elizabeth Heneghan

ONDJAATE, Laura ZaKARAS et Arthur

BROOKS, Gifts of the Muse: Reframing the Debate about the Benefits of Arts, Rand Research Division, 2004. 
Jim McGuigan, Cool Capitalism, Pluto Press, 2009.

Alison J. McINTOSH et Anna Siggs, "An exploration of the experiential nature of boutique accommodation", Journal of Travel Research, vol. 44, n I, 2005.

Anna J. Mclntosh et Richard C. Prentice, "Affirming authenticity: consuming cultural heritage", Annals of Tourism Research, vol. 26, $n^{\circ} 3,1999$.

Kevin Meethan et Julian Beer, "Economic Clustering, Tourism and the Creative Industries in Plymouth: Developing a practical Tool for Impact Assessment", Greg RICHARDS et Julie WILSON (dir.), Tourism, Creativity and Development, Routledge, 2007. Yves MichaUd, L'Art à l'état gazeux. Essai sur le triomphe de l'esthétique, Stock, 2003.

Patrick K.-W Mok, "Hong Kong's cultural and creative industries in a decade: a decade with stagnant growth, uncertainty and unsettled problems", dans Y. D. LIN (dir.), International Classic Statement of Cultural and Creative Industry, Taipei City, Shtabook, 2010.

Kjell OLSEN, "Authenticity as a concept in tourism research: the social organization of the experience of authenticity", Tourist Studies, vol. 2, n², 2002.

Can-Seng Ool, Cultural Tourism and Tourism Cultures: The Business of Mediating Experiences in Copenhagen and Singapore, Copenhagen Business School Press, 2002. Can-Seng Ool, "The creative industries and tourism in Singapore", dans Greg RICHARDS et Julie WILSON (dir.), Tourism, Creativity and Development, Routledge, 2007.

Haemoon $\mathrm{OH}$, Anne Marie FIORE et

Myyoung JEOUNG, "Measuring experience economy concepts: tourism applications", Journal of Travel Research, vol. 46, n², 2007. Julie E. Otto et Brent R. RITCHIE, "The ser- vice experience in tourism", Tourism Management, vol. 17, n³, 1996.

Thomas PARIS, "Organisation, processus et structures de la création", Culture prospective, $\mathrm{n}^{\circ} 5,2007$

Thomas PARIS, "Le nouvel Eldorado des industries créatives", dans Anne GOMBAULT et Florine LIVAT-PÉCHEUX (dir.), Alphabem des industries créatives, Éditions BEMBordeaux Management School, 2009.

Nick PERRY, Hyperreality and Global Culture, Routledge, 1998.

Michel PICARD, Bali. Tourisme culturel et culture touristique, L'Harmattan, 1992.

B. Joseph PINE et James H. GILMORE,

"Welcome to the experience economy", Harvard Business Review, juillet-août 1998. B. Joseph PINE et James H. GILMORE, The Experience Economy: Work is Theater and Every Business a Stage, Harvard Business School Press, 1999

Auliana Poon, Tourism, Technology and Competitive Strategies, Cabi Publishing, 1993.

Michael E. PORTER, Competitive Strategy, The Free Press, 1980.

Richard C. Prentice, Stephen F. Witt et

Claire Hamer, "Tourism as experience: the case of heritage parks", Annals of Tourism Research, vol. 25, $\mathrm{n}^{\circ} \mathrm{I}, 1998$.

Shuai Quan et Ning WANG, "Towards a structural model of the tourist experience: an illustration from food experiences in tourism", Tourism Management, vol. 25, n³, 2004

Peter Quatermaine et Bruce Peter, Cruise: Identity, Design and Culture, Laurence King Publishing, 2003.

Greg RICHARDS (dir.), Developing and Marketing Crafts Tourism, Atlas, 1999.

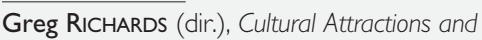
European Tourism, Cabi Publishing, 2001.

Greg RICHARDS, "Creative tourism as a fac- tor in destination development", dans Neil ANDREWS, Sheila FLANAGAN and Joseph RUDDY (dir.), Innovation in Tourism Planning, Dublin Institute of Technology, 2002.

Greg RICHARDS, "Creativity: a new strategic resource for tourism", dans John

SWARBROOKE, Melanie K. SMITH et Leontine OnderWATER (dir.), Tourism, Creativity and Development: Atlas Reflections 2005, Atlas, 2005.

Greg RiCHARDS (dir.), Cultural Tourism: Global and Local Perspectives, Haworth Press, 2007.

Greg RICHARDS, The Impact of Culture on Tourism, OCDE, 2009a.

Greg RICHARDS, "Increasing the attractiveness of places through cultural resources", Tourism, Culture and Communication, vol. 9 $n^{\circ} 3,2009 b$

Greg RICHARDS, "Tourism development trajectories. From culture to creativity", Journal of Tourism and Management Studies, $201 \mathrm{I}$.

Greg RICHARDS, "Creativity and tourism. The state of the art", Annals of Tourism Research, Vol. 38, n. 4, 2011 .

\section{Greg RICHARDS et Crispin RAYMOND,}

"Creative tourism", Atlas News, n 23, 2000

Greg RICHARDS et Julie WILSON,

"Developing creativity in tourist experiences: a solution to the serial reproduction of culture?", Tourism Management, vol. 27, 2006

Greg RICHARDS et Julie WILSON (dir.),

Tourism, Creativity and Development,

Routledge, 2007a.

Greg RICHARDS et Julie WILSON, "The creative turn in regeneration: creative spaces, spectacles and tourism in cities", dans Melanie K. SMITH (dir.), Tourism, Culture and Regeneration, Cabi, 2007b.

Greg RICHARDS et Julie WILSON, Changing Structures of Collaboration in Cultural Tourism, Atlas, 2008a.

Greg RICHARDS et Julie WILSON, Changing 


\section{CHRONIQUE SCIENTIFIQUE}

Places. The spatial challenge of creativity,

Atlas, 2008b

Georges RITZER, Enchanting a Disenchanted World. Revolutionizing the Means of Consumption, Pine Forge Press, 1999.

\section{$\overline{\text { Georges RITZER }}$ et Allen LISKA,}

'“McDisneyization' and 'Post-Tourism': complementary perspectives on contemporary tourism", dans Chris RoJEK et John URRY (dir.), Touring Culture, Routledge, 1997.

Georges Ritzer et Todd StilLman, "The modern Las Vegas Casino-Hotel: the paradigmatic new means of consumption", M@n@gement, vol. 4, n³, 200 I.

Chris Rojek, Ways of Escape: Modern Transformations in Leisure and Travel,

Routledge, 1993.

Chris RoJeK et John URRY, Touring Cultures: Transformations of Travel and Theory,

Routledge, 1997.

Heike A. SCHANZEL et Alison J. MCINTOSH, "An insight into the personal and emotive context of wildlife viewing at the Penguin Place, Otago Peninsula, New Zealand", Journal of Sustainable Tourism, 8(I), 2000.

Allen J. ScotT, The Cultural Economy of Cities: Essays on Geography of ImageProducing Industries, Sage, 2000.

Allen J. SCOTT et Frédéric LeRICHE, "Les ressorts géographiques de l'économie culturelle : du local au mondial", L'Espace géographique, $n^{\circ}$ 3, 2005.

Tom SeLWYN, "Introduction", dans Tom SELWYN (dir.), The Tourist Image: Myths and Myth Making in Tourism, Wiley, 1996.

John F. SHeRRY, Servicescapes: The Concept of place in contemporary markets, NTC Business Books, 1998.

Melanie K. SMITH, "Introduction", dans John SWARBROOKE, Melanie K. SMITH, et Leontine ONDERWATER (dir.), Tourism, Creativity and
Development: Atlas Reflections 2005, Atlas, 2005a.

Melanie K. SMITH, "New leisure tourism: fantasy futures", dans Dimitrios BUHALIS et Carlos COSTA (dir.), New Tourism Consumers, Products and Industry: Present and Future Issues, Butteworth-Heinemann, 2005b.

Melanie K. SMITH, Issues in Cultural Tourism

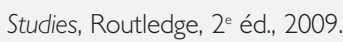

William L. SMITH, "Experiential tourism standards: the perceptions of rural tourism providers", International Journal of Services and Standards, vol. 2, n 3, 2006.

Ernest STERNBERG, "The iconography of the tourism experience", Annals of Tourism Research, vol. 24, n 4, 1997.

Bernard STIEGLER, De la misère symbolique, tomes I et II, Éditions Galilée, 2004 et 2005.

David M. StIPANUK, Hospitality Facilities

Management and Design, Educational Institute of the American Hotel and Motel Association,

3e éd., 2006.

Don TAPscott, The Digital Economy: Promise and Peril In The Age of Networked Intelligence, McGraw-Hill, 1995.

David THROSBY, Economics and Culture, Cambridge University Press, 200I.

David THROSBY, "Introduction and overview", dans Victor A. GINSBURGH et David THROSBY (dir.), Handbook of the Economics of Art and Culture, volume I, North-Holland, 2006.

David THROSBY, "From cultural industries to creative industries", 3es Joumées d'économie de la culture : nouvelles frontières de l'économie de la culture, Musée du quai Branly, 2008.

Alvin TOFfLER, The Third Wave, Bantam Books, 1980.

Gaëtan TREMBLAY, "Industries culturelles, économie créative et société de l'information", Global Media Journal, Canadian edition, vol. I, n० I, 2008.

Rémy TREMBLAY et Diane-Gabrielle

TREMBLAY, La Classe créative selon Richard

Florida ; un paradigme urbain plausible ?,

Presses de l'Université du Québec, 2010.

Graham TURNER, "Tourism and the arts: let's work together", Insights, vol. 3, n 3 , 1992.

Jean-Didier URBAIN, Les Vacances, Le Cavalier Bleu, 2002.

John URRY, The Tourist Gaze :Leisure and Travel in Contemporary Societies, Sage, 1990 (nouv. éd., 2002)

Thierry VERSTRAETE et Estelle JOUISONLAFFITTE, "A conventionalist theory of the business model in the context of business creation for understanding organizational impetus", Management International, vol. 15 $n^{\circ} 2,2011$.

Richard VÉZINA, "Pour comprendre et analyser l'expérience du consommateur', Gestion, vol. 24, n² 2, 1999.

Elsa VIVANT, Qu'est-ce que la ville créative? Puf, 2009.

Ning WANG, "Rethinking authenticity in tourism experience", Annals of Tourism Research, vol. 26, 1999.

Work Foundation, Staying Ahead. The Economic Performance of the UK's Creative Industries, Work Foundation-Department for Culture, Media and Sport, 2007.

\section{Yi-Hua YUAN et Chihkang Wu,}

"Relationship among experiential marketing, experiential value, and customer satisfaction", Joumal of Hospitality and Tourism Research, vol. 32, n³, 2008.

Anne ZAHRA, "Destination management obstacles to creativity and a creative response from local government in $\mathrm{New}$ Zealand", Atlas Annual Conference 2005, Tourism Creativity and Development, Barcelone. 